\title{
Is it worth reading this paper?
}

\section{Derek Richards}

\section{Director, Centre for Evidence-based Dentistry, Oxford, UK}

How often have you asked yourself that question? Equally when you have finished reading a paper (or stopped reading it halfway through) how often have you asked what were they talking about? Or do you think, it's a good journal, they must know what they are talking about, I must be getting dull!

As clinicians we need to be able to decide whether a particular treatment is worthwhile. If a new diagnostic test is better or more efficient than what was available previously; e.g. is E-speed Xray film better than $\mathrm{D}$-speed, or should we all be using digital radiography.

In today's technological world we are faced with a mountain of information from different sources; books, journals, electronic journals, manufacturers' and distributors' information sheets. So how do we decide whether it is any good?

Traditionally we might have looked at well-known standard textbooks or at papers in peer-reviewed journals. We might also look at the name of the author, or the institute from whence the authors came. If the authors or the institute had a good name or reputation we might then be more inclined to read them or give them more weight. But is this appropriate?

When deciding if papers are any good a favoured method of readers is to look first at the introduction or abstract and conclusions. However, it is not unusual to find that often conclusions drawn from research papers are not related to the results presented or that the methodology used is able to answer the research question posed.

So how can we assess whether a paper is worth reading? One method of achieving this is to have a systematic process of assessing the reliability, relevance and results of published papers. This is referred to as critical appraisal or critical reading. Critical appraisal can be practised by anyone with access to appropriate methodologically sound appraisal criteria. Appraisal criteria can be found at several websites and there are also several books and CD-ROMs that now give information on how to carry this out.

However, despite that range of criteria available for appraisal of papers there are only three essential questions that need to be asked of any paper:

Is the study valid?

What are the results?

Are the results relevant?

\section{Is the study/paper valid?}

By valid we mean was the study conducted properly. This is also referred to as a study's internal validity, hence the question. To assess a study's internal validity we can ask a number of subsidiary questions.

Did the authors ask a clear question? Authors usually have either an aim, objective or for an experimental design, such as a randomised-controlled trial, a hypothesis that they wish to test e.g. does 'allstick' composite have longer survival rates, better marginal adaptation, or colour stability than 'hardasnails' composite, or will 'germreducto' toothpaste result in better periodontal condition for patients than the older 'wisowhite' toothpaste.

If the authors themselves are not clear what they are hoping to find or prove you may also be none the wiser. Lack of clarity in relation to what the authors are trying to achieve may also result in using an inappropriate study design to address the question, which brings us on to the next question.

Did they use the most appropriate study design?

When testing the efficacy of drug treatments, surgical procedures, alternative methods of service delivery, or other interventions, the preferred design is the randomised-controlled trial or a systematic review or several RCTs. When determining the outcome (prognosis) of someone with a disease detected at an early stage a cohort study is the best design, whereas, if we are looking to understand the views, perceptions or beliefs of patients we need to conduct qualitative research of appropriate methodology.

Table 1 sets out the appropriate design for different types of questions.

Was the study carried out reliably?

We need to be sure that the study was carried out reliably. For example if the

Table 1 Appropriate study designs

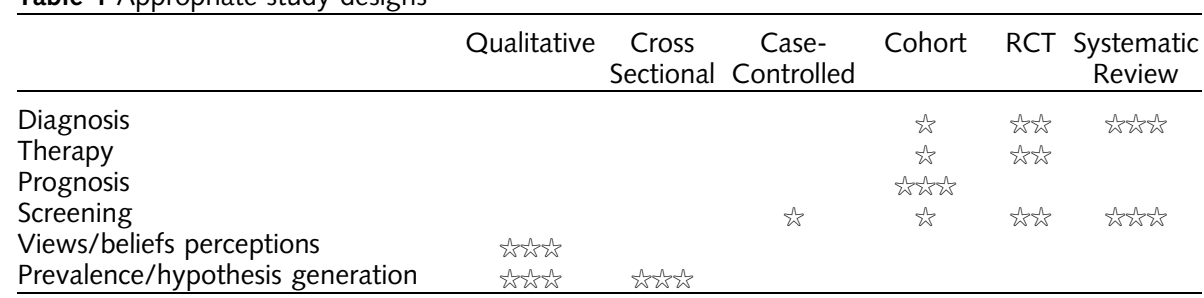

* The greater the number of stars the more appropriate the study design. 
study is a RCT the randomisation needs to have been conducted properly using an appropriate technique.

Are the methods clearly described so others can see what has been done?

The methods used to conduct the study must be clearly described so you can see what has been done to allow reproducibility. For RCTs and systematic reviews there is now a standardised reporting format. For RCTs this is called CONSORT and for systematic reviews is QUOROM.

\section{What are the results?}

If the study has been carried out properly you can look to the results. We can then ask

\section{Is there a clear result?}

Are the results presented clearly using appropriate statistical tests?

Having a clear result or bottom line is important to most researchers, yet it is often wrapped up in complex statistical tests or jargon. Appraising whether the appropriate tests have been used is often more difficult without a degree of background statistical knowledge. However, a number of groups run courses in critical appraisal techniques which include the basic statistical knowledge needed to appraise papers.

Another important element in assessing the result is differentiating between statistical and clinical relevance. For example if we are comparing two periodontal treatments, and after 6 months there is a statistically significant reduction in pocket depth, say of 0.1 or $0.2 \mathrm{~mm}$, is this important clinically? Probably not, particularly when there is a recognised error rate in recording the depth of pockets. Concern over clinical relevance of results has led to increasing use of the confidence intervals. Confidence intervals show the uncertainty or lack or precision in the result and convey more useful information than the $\mathrm{P}$ value. (The $\mathrm{P}$ value will be less than 0.05 [i.e. significant] only when the $95 \%$ confidence interval does not include zero or more generally the value specified in the null hypothesis.)

\section{Are the results relevant?}

Once you have appraised the internal validity and the results of the paper you can ask if they are relevant.

What we mean here is, are the results relevant to my patients. Are the group of patients on whom the research was carried out similar enough to the ones I see every day to apply the findings of the paper to them. The other issue, which you need to consider, is your own resources in terms of time and equipment. The study may be valid and the result clinically important but, is it realistic for you to apply what was done in the study to your patients. This is termed generalisability and it is often an issue. You may recall the recent National Institute of Clinical Excellence (NICE) decision regarding the anti-flu medication, which was not recommended for use in the NHS. One of the reasons was that although studies had shown it to be effective none had been carried out on the age group under discussion.

The type of critical appraisal outlined above is based on looking in detail at the methodology and results of the paper, rather than the introduction and conclusions. Well-developed appraisal criteria for a wide range of study designs are now available from a range of websites and texts, some of which are listed below.

\section{Further reading}

Begg C, Cho M, Eastwood S, Horton R, Moher D, Olkin I, Pitkin R, Rennie D, Schulz KF, Simel D, Stroup DF. Improving the quality of reporting of randomized controlled trials. The CONSORT statement. JAMA 1996; 276:637-639.

Moher D, Cook DJ, Eastwood S, Olkin I, Rennie $D$, Stroup DF, for the QUOROM Group. Improving the quality of reports of metaanalyses of randomised controlled trials: the QUOROM statement. The Lancet 1999; 354: 1896-1900.

\section{Books}

Crombie IK. The pocket guide to critical appraisal. BMJ: London; 1996.

Greenhalgh T. How to read a paper, the basics of evidence based medicine. BMJ: London; 1997.

\section{Users guides}

Guvatt GH, Rennie D (eds). Users guides to the medical literature. JAMA 1993; 270: 20962097.
Oxman AD, Sackett DL, Guyatt GH. Users guides to the medical literature. I. How to get started. JAMA 1993; 270: 2093-2095.

Guvatt GH, Sackett DW, Cook DJ. Users guides to the medical literature. II. A. How to use an article about therapy or prevention. JAMA 1993; 270: 2598-2601.

Guvatt GH, Sackett DL, Cook, DJ. Users guides to the medical literature. II. B. How to use an article about therapy or prevention: What were the results and will they help me in caring for my patients? JAMA 1994; 271: 59-63.

Jaeschke R, Guyatt GH, Sackett, DL. Users guides to the medical literature. III. How to use an article about a diagnostic test $A$. Are the results of the study valid? JAMA 1994; 271: 389-391.

Jaeschke R, Guyatt GH, Sackett DL. Users Guide to the Medical Literature. III. How to use an article about a diagnostic test. B. What are the results and will they help me in caring for my patients? JAMA 1994; 271 : 703-707.

Levine $M$, W'alter $S$, Lee $H$, Haines I, Holbrook A, Moyer V. Users guide to the Medical Literature. IV. How to use an article about harm. JAMA 1994; 271: 1615-1619.

Laupacis A, Wells G, Richardson WS, et al, for the Evidence Based Medicine Working Group. Users Guide to the Medical Literature. V. How to use an article about prognosis. JAMA 1994; 272: 234-237.

Oxman AD, Cook DJ, Guyatt G. Users Guide to the Medical Literature. VI. How to use an overview. JAMA 1994; 272: 1367-1371.

Richardson WS, Detsky AS. Users Guide to the Medical Literature. VII. How to use a Clinical Decision Analysis. A. Are the results of the study valid? JAMA 1995; 273: 12921295.

Richardson WS, Detsky AS. Users Guide to the Medical Literature. VII. How to use a Clinical Decision Analysis. B. What are the results and will they help me in caring for my patients? JAMA 1995; 273: 1610-1613.

Hayward RSA, Wilson MC, Tunis SR, Bass EB, Guyatt $G$. Users Guide to the Medical Literature. VIII. How to use clinical practice guidelines. A. Are the recommendations valid? JAMA 1995; 274: 570-574.

Wilson MC, Hayward RSA, Tunis SR, Bass EB, Guyatt G. Users Guide to the Medical Literature. VIII. How to use clinical practice guidelines. B. What are the recommendations and will they help you in caring for your patients? JAMA 1995; 274: 1630-1632.

Guvatt GH, Sackett DL, Sinclair JC, Haywards, R, Cook DJ, Cook RJ. Users Guide to the Medical Literature. IX. A method for grading health care recommendations. JAMA 1995; 274: 1800-1804.

Naylor CD, Guyatt GH. Users Guides to the Medical Literature. X. How to use an article reporting variations in the outcomes of health services. JAMA 1996; 275: 554-558. 
Naylor CD, Guyatt GH. Users Guides to the Medical Literature. XI. How to use an article about a clinical utilization review. JAMA 1996; 275: 1435-1439.

Guyatt $G H$, Naylor CD, Juniper E, et al. Users Guides to the Medical Literature .XII. How to use articles about health-related quality of life. JAMA 1997; 277: 1232-37.

Drummond MF, Richardson WS, O'Brien BJ, Levine M, Heyland D. Users' Guides to the Medical Literature. XIII. How to use an article on economic analysis of clinical practice. A. Are the results of the study valid? JAMA 1997; 277:1552-1557.

O'Brien BJ, Heyland D, Richardson WS, Levine $M$, Drummond MF. Users Guides to the Medical Literature. XIII. How to use an article on economic analysis of clinical practice. $B$. What are the results and will they help me in caring for my patients? [published erratum appears in JAMA 1997; 278: 1064]. JAMA 1997; 277: 1802-1806.

Dans AL, Dans LF, Guyatt GH, Richardson S. Users Guides to the Medical Literature. XIV. How to decide on the applicability of clinical trial results to your patient. JAMA 1998; 279: 545-549.

Richardson WS, Wilson MC, Guyatt GH, Cook DJ, Nishikawa J. Users Guides to the Medical Literature. XV. How to use an article about disease probability for differential diagnosis. JAMA 1999; 281:1214-1219.

Guyatt GH, Sinclair J, Cook DJ, Glasziou, P. Users Guides to the Medical Literature. XVI. How to use a treatment recommendation. JAMA 1999; 281:1836-1843.

Barratt A, Irwig L, Glasziou $P$, et.al. Users Guides to the Medical Literature. XVII. How to use guidelines and recommendations about screening. JAMA 1999; 281: 29.
Randolph AG, Haynes RB, Wyatt JC, Cook DJ, Guyatt $\mathrm{GH}$. Users Guides to the Medical Literature. XVIII. How to use an article evaluating the clinical impact of a computer-based clinical decision support system. JAMA 1999; 282: 67-74.

Bucher HC, Guyatt GH, Cook DJ, Holbrook A, McAlister FA. Users Guides to the Medical Literature. XIX. Applying clinical trial results. A. How to use an article measuring the effect of an intervention on surrogate end points. JAMA 1999; 282:771-778.

McAlister FA, Laupacis A, Wells GA, Sackett DL. Users Guides to the Medical Literature. XIX. Applying clinical trial results. B. Guidelines for determining whether a drug is exerting (more than) a class effect. JAMA 1999; 282:1371-1377.

McAlister FA, Straus SE, Guyatt GH, Haynes RB. Users Guides to the Medical Literature. XX. Integrating research evidence with the care of the individual patient. JAMA 2000; 283:2829-2836.

Hunt DL, Jaeschke $\mathrm{R}$, McKibbon KA. Users Guides to the Medical Literature. XXI. Using electronic health information resources in evidence-based practice. JAMA 2000; 283:1875-1879.

McGinn TG, Guyatt GH, Wyer PC, Naylor CD, Stiell IG, Richardson WS. Users' Guides to the Medical Literature. XXII. How to use articles about clinical decision rules. JAMA 2000; 284:79-84.

Giacomini MK, Cook DJ. Users Guides to the Medical Literature. XXIII. Qualitative research in health care. A. Are the results of the study valid? JAMA 2000; 284:357362.

\section{Basic statistics}

Guyatt GH, Jaeschke R, Heddle N, Cook D, Shannon H, Walter S. Basic statistics for clinicians: 1. Hypothesis testing. Canadian Medical Association Journal 1995; 152: 2732

Guyatt $G H$, Jacschke R, Heddle N, Cook D, Shannon H, Walter S. Basic Statistics for clinicians: 2. Interpreting Study Results: Confidence Intervals. Canadian Medical Association Journal 1995; 152: 169-173.

Jaesechke R, Guyatt GH, Shannon II, Walter S, Cook D, Heddle N. Basic statistics for clinicians: 3. Assessing the effects of treatment: measures of association. Canadian Medical Association Journal 1995; 152: 35-37.

Guyatt GH, Walter S, Shannon H, Cook D, Jaeschke $R$, Heddle N. Basic statistics for clinicians: 4. Correlation and regression. Canadian Medical Association Journal 1995; 152: 497-504.

\section{Websites}

Centre for Evidence-based Dentistry http://www.cebd.org

Critical Skills Appraisal Programme CASP http://www.public-health.org.uk/casp/

Trent Research Internet Access Gateway TRIAGE http://www.shef.ac.uk/ scharr/triage/

Evidence-based Medicine Resource Centre http://www.ebmny.org/

Agency for HealthCare and Research Quality http://www.ahrq.gov/

Canadian Centre for Health Excellence http://www.cche.net/ 